Article

\title{
The Potential of a Tailored Biomimetic Hydrogel for In Vitro Cell Culture Applications: Characterization and Biocompatibility
}

\author{
Yung-Chieh Cho ${ }^{1,2}$, Hsiao-Ting Huang ${ }^{3,+}$, Wen-Chien Lan ${ }^{4}$, Mao-Suan Huang ${ }^{5,6}$, \\ Takashi Saito ${ }^{7}\left(\mathbb{D}\right.$, Bai-Hung Huang ${ }^{2,8,9}$, Chi-Hsun Tsai ${ }^{7}$, Fang-Yu Fan ${ }^{2,10}$ (D) and \\ Keng-Liang Ou 2,4,5,7,11,*(D) \\ 1 School of Dentistry, College of Oral Medicine, Taipei Medical University, Taipei 110, Taiwan; \\ D204106003@tmu.edu.tw \\ 2 Biomedical Technology R \& D Center, China Medical University Hospital, Taichung 404, Taiwan; \\ T33782@mail.cmuh.org.tw (B.-H.H.); fish884027@tmu.edu.tw (F.-Y.F.) \\ 3 Division of Oral Rehabilitation and Center of Pediatric Dentistry, Department of Dentistry, Taipei Medical \\ University Hospital, Taipei 110, Taiwan; b202097053@tmu.edu.tw \\ 4 Department of Oral Hygiene Care, Ching Kuo Institute of Management and Health, Keelung 203, Taiwan; \\ jameslan@ems.cku.edu.tw \\ 5 Department of Dentistry, Taipei Medical University-Shuang Ho Hospital, New Taipei City 235, Taiwan; \\ hms4837@tmu.edu.tw \\ 6 School of Oral Hygiene, College of Oral Medicine, Taipei Medical University, Taipei 110, Taiwan \\ 7 Division of Clinical Cariology and Endodontology, Department of Oral Rehabilitation, School of Dentistry, \\ Health Sciences University of Hokkaido, Hokkaido 061-0293, Japan; t-saito@hoku-iryo-u.ac.jp (T.S.); \\ e526095019@tmu.edu.tw (C.-H.T.) \\ 8 Asia Pacific Laser Institute, New Taipei City 220, Taiwan \\ 9 Implant Academy of Minimally Invasive Dentistry, Taipei 106, Taiwan \\ 10 Department of Dental Technology, College of Oral Medicine, Taipei Medical University, Taipei 110, Taiwan \\ 11 3D Global Biotech Inc. (Spin-off Company from Taipei Medical University), New Taipei City 221, Taiwan \\ * Correspondence: klou@tmu.edu.tw \\ + Co-first author: Hsiao-Ting Huang.
}

Received: 23 October 2020; Accepted: 14 December 2020; Published: 17 December 2020

check for updates

Featured Application: The potential application of the work is in the area of three-dimensional cell culture in vitro.

Abstract: In this study, the Pluronic F127 with modified tripeptide Gly-Arg-Gly-Asp copolymer (hereafter defined as 3BE) hydrogel was evaluated in terms of its biocompatibility potentials. The fibroblasts (Swiss 3T3 cell line) and human hair follicles-derived mesenchymal stem cells (HFMSCs) were cultured in different concentrations of the 3BE hydrogel $(0 \%, 0.05 \%, 0.1 \%, 0.25 \%$, and $0.5 \%$, respectively). The cell morphology and differentiation potential of HFMSCs were observed through optical microscopy, and the cell viability was investigated via Live/Dead Kit and Cell Counting Kit-8 assay. Analytical results showed that HFMSC can differentiate into adipogenic, chondrogenic, and osteogenic lineages. The HFMSC and Swiss 3T3 cells would properly assemble into a spherical shape as cultured with the 3BE hydrogel. Most importantly, cell viability could be maintained above $70 \%$. The formation of spheroid structures of cells within this hydrogel is predicted to promote cell differentiation potentials of HFMSC that benefit in generating functional adipocytes, chondrocytes, and osteoblasts. Therefore, these findings demonstrate that the 3BE hydrogel has great potential as a three-dimensional cell culture scaffold for tissue engineering applications.

Keywords: pluronic F127; tripeptide Arg-Gly-Asp; spheroids; hair follicle; mesenchymal stem cells 


\section{Introduction}

Nowadays, massive advances have been made in research fields to improve cell culture techniques [1-3]. Previously, a model of a two-dimensional (2D) monolayer cell culture was the fundamental technique for cellular research [4]. However, this technique often failed to fully imitate the cellular functions and behaviors of cells [4,5]. In addition, in a 2D cell culture, the microenvironment is not physiologically uniform due to the absence of nutrients, oxygen, and extracellular matrix (ECM), which leads to a failure in exhibiting the cell development process [6,7]. Other limitations of this method, such as loss of cell mechanical and biochemical signals, loss of tissue-specific architecture, loss of cell-to-cell interactions, and loss of cell-to-matrix interaction have also been reported $[4,8,9]$. Due to this fact, it is crucial to develop a suitable environment to properly nourish cells and preserve cell growth and proliferation $[4,10]$. In this way, a three-dimensional (3D) cell culture has emerged as the current state-of-the-art, providing better cellular characteristics of an in vivo environment for cells [5]. In light of that, numerous modifications have been proposed to improve cell growth in three dimensions, some of them are increasing scaffold bioactivity and using a scaffold for cells [11,12]. Nevertheless, in this technique, the challenge for a more sophisticated scaffold system to support and facilitate cell growth and desirable tissue formation needs to be considered [2].

In recent years, Pluronic F127 hydrogel has attracted particular interest in 3D cell culture [13]. Unique characteristics of F127 such as thermo-reversible, micellar properties, and gelation behavior with excellent solubility allowed this polymer to be used as a carrier for drug delivery, controlled-release, and tissue engineering applications [14]. A previous study investigated the potential of F127 as a cell encapsulation material using a human hepatic carcinoma cell [13]. Additionally, F127 as graft materials has also been proved to facilitate the growth and differentiation of mesenchymal stem cells (MSCs) into osteogenic lineage $[15,16]$. In spite of that, high demand still exists for the formulation of this material purposing to ameliorate cell growth, proliferation, and differentiation when seeding the cells in vitro [5].

Arg-Gly-Asp (RGD) is an integrin-binding site, which belongs to the class of adhesive proteins [17]. The RGD region is found in various proteins and is crucial for facilitating cell-adhesive activity. Moreover, it has been reported that the Gly-Arg-Gly-Asp (GRGD) peptide sequence is identical to the cell-binding region of fibronectin protein [18]. Therefore, the present study aimed to investigate the F127 with modified GRGD copolymer (hereafter defined as 3BE) hydrogel in its biocompatibility with distinct cell types. In this study, we used human hair follicle-derived mesenchymal stem cells (HFMSCs) due to its easy accessibility $[19,20]$. The HFMSC has been proved to have similar characteristics with bone marrow-derived MSCs and is suggested as an important and alternative source for MSC [20].

\section{Materials and Methods}

\subsection{Synthesis of the $3 B E$ Hydrogel}

Before synthesis, Pluronic ${ }^{\circledR}$ F127 (F127; Sigma 0.709 mmol, Taipei, Taiwan) was dissolved in $90 \mathrm{~mL}$ of toluene at $25^{\circ} \mathrm{C}$. Afterward, 4-methacryloxyethyl trimellitic anhydride (4-META; Sigma $1.687 \mathrm{mmol}$, Taipei, Taiwan), 4-(dimethyl amino)-pyridine (DMAP; Sigma $0.709 \mathrm{mmol}$, Taipei, Taiwan), and triethylamine (TEA; Sigma $0.709 \mathrm{mmol}$, Taipei, Taiwan) were added to the dissolved F127. Then, the reaction mixture was stirred with a magnetic stirring bar at $25^{\circ} \mathrm{C}$ for $16 \mathrm{~h}$ under a nitrogen atmosphere. Diethyl ether (Sigma, Taipei, Taiwan) was then added to the reaction solution to form a precipitate. The precipitate was filtered and dried with high vacuum pressure to gain the F127-4-META. Subsequently, the F127-4-META was dissolved in $15 \mathrm{~mL}$ of anhydrous tetrahydrofuran (Sigma, Taipei, Taiwan) at $25^{\circ} \mathrm{C}$. The N-hydroxysuccinimid (NHS Sigma $4.650 \mathrm{mmol}$, Taipei, Taiwan), $\mathrm{N}, \mathrm{N}^{\prime}$-dicyclohexylcarbodiimide (Sigma $4.650 \mathrm{mmol}$, Taipei, Taiwan), and 4-(dimethylamino) pyridine (Sigma, Taipei, Taiwan) were added to the dissolved F127-4-META. Next, the reaction mixture was stirred with a magnetic stirring bar at $25^{\circ} \mathrm{C}$ for $16 \mathrm{~h}$ under a nitrogen atmosphere. Diethyl ether was then added to the reaction solution to form a precipitate. The residual solvent was removed to obtain 
the F127-4-META-NHS under high vacuum pressure. After finishing the F127-4-META-NHS synthesis, the F127-4-META-NHS, GRGD (RDD Lab. Inc., New Taipei City, Taiwan), and triethylamine (Sigma $0.218 \mathrm{mmol}$, Taipei, Taiwan) were added to a solution containing $2.6 \mathrm{~mL} \mathrm{~N}, \mathrm{~N}$-dimethylformamide (DMF; Sigma, Taipei, Taiwan). The mixed solution was stirred with a magnetic stirring bar at $25^{\circ} \mathrm{C}$ for $16 \mathrm{~h}$ under a nitrogen atmosphere. Then, the reacted mixture solution was freeze-dried to remove the DMF. Afterward, chilled methanol was added to the reacted mixture solution without DMF to form the precipitate solution. Finally, the precipitate solution was filtered and dried under high vacuum pressure to form the 3BE copolymer powder (F127-4-META-GRGD). In the present study, the copolymer powder was dissolved in a culture medium and prepared as different concentrations of hydrogel ( $0 \%$ (3BE-0), $0.05 \%$ (3BE-1), $0.1 \%$ (3BE-2), $0.25 \%$ (3BE-3), and $0.5 \%$ (3BE-4) for investigation.

\subsection{Spectroscopic Characterization Analysis}

The structure and purity of the modified hydrogels were characterized using nuclear magnetic resonance (NMR) spectroscopy and Fourier-transform infrared (FTIR) spectroscopy. Before NMR characterization, the investigated samples were dissolved in Chloroform-d (deuterochloroform, $\mathrm{CDCl}_{3}$, Sigma-Aldrich, Taipei, Taiwan) solvent. Subsequently, the investigated samples were measured by means of the model Avance DRX 500 spectrometer (Bruker Optics Inc., Billerica, MA, USA) operating at $300 \mathrm{MHz}$. In the FTIR analysis, the investigated samples were fixed with potassium bromide $(\mathrm{KBr})$ for measurements. The FTIR spectra were obtained using the FTIR 410 spectrometer (Jasco Inc., Tokyo, Japan) in the range from 4000 to $500 \mathrm{~cm}^{-1}$ with a resolution of $4 \mathrm{~cm}^{-1}$.

\subsection{Isolation of HFMSCS}

The protocols for human cell investigations were reviewed and approved by the Taipei Medical University-Joint Institutional Review Board under a project identification code of TMU-JIRB N202012035. To acquire HFMSCs, donor hair follicles were uniformly obtained from adult occipital scalps by an ARTAS ${ }^{\circledR}$ robotic system (San Jose, CA, USA). Isolation techniques were designed according to previously established protocol with some modifications. Firstly, the biopsy sample of hair follicles was thoroughly rinsed with phosphate-buffered saline (PBS; Sigma, Taipei, Taiwan) containing penicillin/streptomycin $(\mathrm{P} / \mathrm{S})$, then the excess adipose tissues were removed. After that, the samples were treated with trypsin/EDTA (Sigma, Taipei, Taiwan) at $37^{\circ} \mathrm{C}$ for $30 \mathrm{~min}$ and then digested with dispase at $4{ }^{\circ} \mathrm{C}$ for over $16 \mathrm{~h}$. After the digestion procedure, the hair and scalp portions were separated from the hair follicles using fine forceps, then filtered through a $70 \mu \mathrm{m}$ cell strainer, and washed extensively with PBS. Prior to the proliferation assay, the cells were cultured in a stromal medium (Dulbecco's modified Eagle's medium/F12 (DMEM; Gibco, Taipei, Taiwan) and 10\% fetal bovine serum (FBS; Gibco, Taipei, Taiwan) for 7 days. After 7 days, cells from individual wells were harvested by $0.25 \%$ trypsin in $0.01 \%$ EDTA following centrifugation at $800 \mathrm{rpm}$ for $5 \mathrm{~min}$. The centrifuged liquid was filtered through a $100 \mu \mathrm{m}$ cell strainer. Then, the hair and the scalp were separately transferred into a sterilized 6-well plate and maintained in MSCs culture medium (100 $\mu \mathrm{L}$ DMEM, 10\% FBS, $1 \% \mathrm{P} / \mathrm{S}, 2.45 \mathrm{~g} / \mathrm{L}$ sodium bicarbonate, and $10 \mathrm{ng} / \mathrm{mL}$ human epidermal growth factor). The cells were maintained in a culture dish for 2 weeks and the medium was replaced every 3 days.

\subsection{Multilineage Differentiation of HFMSCs}

In this study, a specific differentiation medium was used to induce human HFMSCs differentiation potential. For adipogenic differentiation, the HFMSCs with density $3 \times 10^{3} \mathrm{cells} / \mathrm{cm}^{2}$ were grown in adipogenic medium including DMEM containing 10\% FBS, $1 \% \mathrm{P} / \mathrm{S}$ antibiotics, $1 \mu \mathrm{M}$ dexamethasone, $0.5 \mathrm{mM}$ isobutyl-methylxanthine, $10 \mu \mathrm{M}$ insulin, and $200 \mu \mathrm{M}$ indomethacin. For chondrogenesis, the cell differentiation was induced by culturing $1 \times 10^{3} \mathrm{HFMSCs} / \mathrm{cm}^{2}$ in the presence of DMEM-high glucose (DMEM-hg) containing 10\% FBS, 1\% P/S antibiotics, $100 \mu \mathrm{M}$ dexamethasone, $0.9 \%$ sodium pyruvate, $50 \mu \mathrm{g} / \mathrm{mL}$ ascorbic acid, $10 \mathrm{ng} / \mathrm{mL}$ transforming growth factor beta $1,5 \mathrm{ng} / \mathrm{mL}$ basic fibroblast growth factor, $1 \%$ insulin-transferrin-selenium, and $40 \mu \mathrm{g} / \mathrm{mL}$ L-proline. For osteogenic differentiation 
potential, the HFMSCs were induced with an osteogenic medium at a density of $6 \times 10^{3} \mathrm{cells} / \mathrm{cm}^{2}$ per 35-mm dish and incubated in the DMEM-hg containing 1\% FBS, 1\% P/S antibiotics, $0.1 \mu \mathrm{M}$ dexamethasone, $50 \mu \mathrm{M}$ of ascorbic acid, and $10 \mu \mathrm{M} \beta$-glycerophosphate. The cells were cultured for 28 days (the medium was changed every 3 days). After the end of the cell culture period, the cells were stained with Oil Red O Kit (adipogenic), Alcian Blue Kit (chondrogenesis), and Alkaline Phosphatase Kit (osteogenic), respectively. A model FV1000/IX81 inverted fluorescence microscope (Olympus, Tokyo, Japan) was employed to observe the morphology of the stained cells under different magnifications.

\subsection{Cell Seeding in the 3BE Hydrogel}

HFMSCs and Swiss $3 \mathrm{~T} 3$ fibroblasts (ATCC ${ }^{\circledR}$ CCL-92 ${ }^{\mathrm{TM}}$, Union Biomed Inc., Taipei, Taiwan) were used for in vitro experiments. Both cells were separately expanded in culture mediums in a humidified $5 \% \mathrm{CO}_{2}$ environment at $37^{\circ} \mathrm{C}$. When the cells reached the appropriate number of cells needed, they were respectively re-suspended from the plate by trypsin, counted, and inoculated in 96-well plates $(100 \mu \mathrm{L} /$ well). The cells were mixed inside different concentrations of the 3BE hydrogel respectively, each well contains $1 \times 10^{3}$ cells/well of Swiss 3T3 and $1 \times 10^{5}$ cells/well of HFMSCs. After this procedure, the plates were pre-incubated for 1 day in a humidified incubator $\left(37^{\circ} \mathrm{C}\right.$, $5 \% \mathrm{CO}_{2}$ ), and then the bright-field images of the attached cells on the investigated 3BE hydrogels were recorded using the FV1000/IX81 inverted fluorescence microscope (Olympus, Tokyo, Japan) under different magnifications.

\subsection{Cell Live/Dead Observation}

The viability of Swiss 3T3 and HFMSCs in the 3BE hydrogel was evaluated using a Live/Dead Kit after 4 days of incubation. The Live/Dead viability assay was performed according to the manufacturer's recommendation. Cells encapsulating $3 \mathrm{BE}$ hydrogel were incubated at $25^{\circ} \mathrm{C}$ for $30 \mathrm{~min}$ in a solution of $4.0 \mu \mathrm{M}$ ethidium homodimer-1 (EthD-1; Sigma, Taipei, Taiwan) and $2.0 \mu \mathrm{M}$ calcein-AM (Sigma, Taipei, Taiwan) in PBS. Living cells were stained with calcein-AM (green), while dead cells were stained with EthD-1 (red). All images were captured through a FV1000/IX81 inverted fluorescence microscope. This experiment was conducted in triplicate.

\subsection{Cell Live/Dead Assay}

The cell viability and proliferation of Swiss 3T3 and HFMSCs were analyzed by Cell Counting Kit- 8 (CCK; Sigma, Taipei, Taiwan) assay. Before analysis, a highly water-soluble tetrazolium salt solution containing 2-(2-methoxy-4-nitrophenyl)-3-(4-nitrophenyl)-5-(2,4-disulfophenyl)-2H-tetrazolium, and monosodium salt were thawed on the bench-top. The 3BE hydrogel was removed and $100 \mu \mathrm{L}$ of CCK solution was added to each well. The cells were incubated for $5 \mathrm{~h}$ in a $5 \% \mathrm{CO}_{2}$ incubator at $37^{\circ} \mathrm{C}$. After $5 \mathrm{~h}$, the CCK solution was removed and $100 \mu \mathrm{L}$ of dimethyl sulfoxide (Sigma, Taipei, Taiwan) was added. The absorbance was measured at different time intervals (1 day, 4 days, and 7 days) using a microplate reader (BioTek Epoch, Winooski, VT, USA) at $570 \mathrm{~nm}$. The assay was performed in standard 96-well plates and each experiment was performed in triplicate. The results were represented as the percentage of cell proliferation.

\subsection{Statistical Analysis}

Statistical analysis was performed with SPSS 19.0 software (SPSS Inc., Chicago, IL, USA). The Student's t-test was used to compare growth and viability of the cells in five different treatments. The differences were considered statistically significant when $p<0.05$. 


\section{Results}

\subsection{Characteristics of the Chemical Bonding State}

As shown in the ${ }^{1} \mathrm{H}-\mathrm{NMR}$ spectra (Figure 1), the characteristic peaks at 1.10 and 3.40-3.80 ppm belong to the protons of $-\mathrm{CH} 3,-\mathrm{CH}$, and $-\mathrm{CH} 2$ of poly(propylene oxide) unit of $\mathrm{F} 127$, respectively. As the F127 modified with NHS, the characteristic peak at 2.63 ppm exhibits the protons of the NHS unit, indicating the NHS bonded with the F127. In the 3BE hydrogel sample, the disappearance of characteristic peaks at 2.63 ppm revealed that the GRGD peptide was successfully conjugated to the end of the F127-NHS. Figure 2 displays the FTIR spectra of the investigated samples. It was found that the carbonyl band of ester was assigned at $1720 \mathrm{~cm}^{-1}$ belong to the methylene $-\mathrm{CH} 2-$ of F127. While, the stretching of $\mathrm{C}=\mathrm{O}$, labeled as amide functional groups, presents a peak at $1650 \mathrm{~cm}^{-1}$ belong to GRGD. Therefore, these results demonstrated that the GRGD peptide can be successfully conjugated with F127.

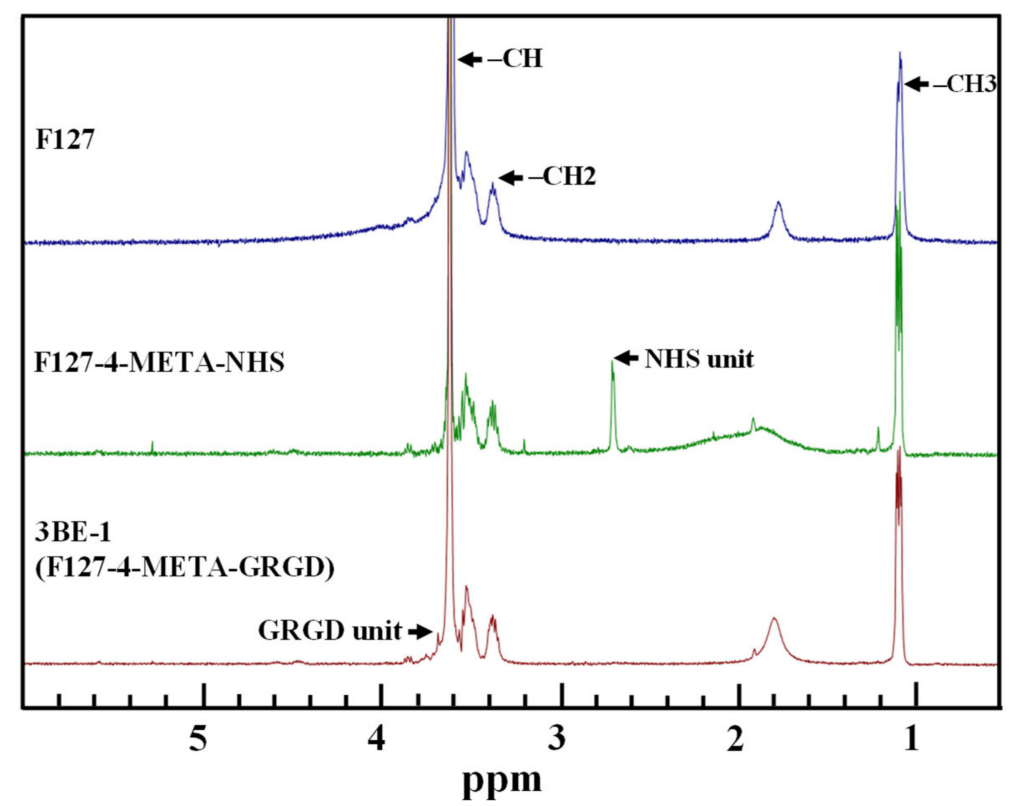

Figure 1. The spectra of ${ }^{1} \mathrm{H}-\mathrm{NMR}$ of the investigated samples. (The characteristic peaks at 1.10 and 3.40-3.80 ppm belong to the protons of $-\mathrm{CH} 3,-\mathrm{CH}$, and $-\mathrm{CH} 2$ of poly(propylene oxide) unit of F127, respectively. The characteristic peak at $2.63 \mathrm{ppm}$ indicating the NHS bonded with the F127. The disappearance of characteristic peaks at $2.63 \mathrm{ppm}$ revealed that the Gly-Arg-Gly-Asp (GRGD)peptide was successfully conjugated to the end of the F127-NHS).

\subsection{Multilineage Differentiation Potential of HFMSCs}

In differentiation experiments, the isolated HFMSCs were cultured under adipogenic, chondrogenic, and osteogenic conditions to observe the differentiation capacity of HFMSCs in three different lineages. Figures 3-5 depict the morphology change of HFMSCs under adipogenic, chondrogenic, and osteogenic conditions. The HFMSCs showed positive results for Oil Red O, Alcian Blue, and Alkaline Phosphatase staining, respectively. Figure 3b shows the droplets began to appear on day 12, which means adipogenic genes had been expressed before day 12 as compared with Figure 3a. This data indicated that the isolated HFMSCs could differentiate into adipogenic lineages. Figure $4 \mathrm{~b}$ shows the chondrogenic medium induced the aggregation of HFMSCs, the cells gradually condensed into compact structures in 28 days highlighting chondrogenic lineages as compared with Figure 4a. This finding indicated that HFMSCs have significant chondrogenic potential. Next, we tested the ability of HFMSCs to differentiate into osteocytes. Figure $5 b$ presents that osteogenic differentiation medium induced HFMSC s transformation in comparison to Figure 5a. Overall, the results demonstrated 
that the isolated HFMSCs have the ability to differentiate into adipocytes, chondrocytes, and osteocytes. Therefore, HFMSCs could be an ideal cell type for generating functional adipocytes, chondrocytes, and osteocytes for tissue engineering applications.

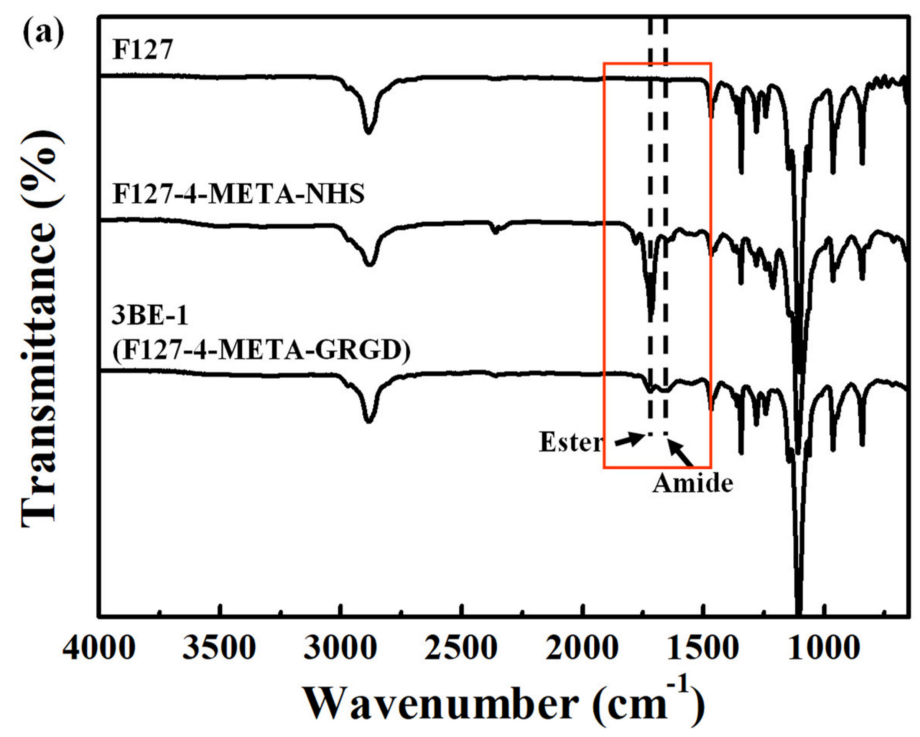

(b)
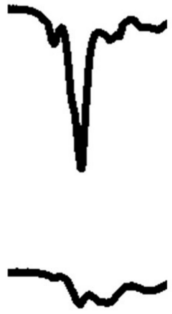

Figure 2. (a) The spectra of FTIR of the investigated samples and (b) a higher magnification image taken from the red cubic area in (a). (The stretching of $\mathrm{C}=\mathrm{O}$, labeled as amide functional groups, presenting a peak at $1650 \mathrm{~cm}^{-1}$ belong to GRGD, which can be successfully conjugated with F127).
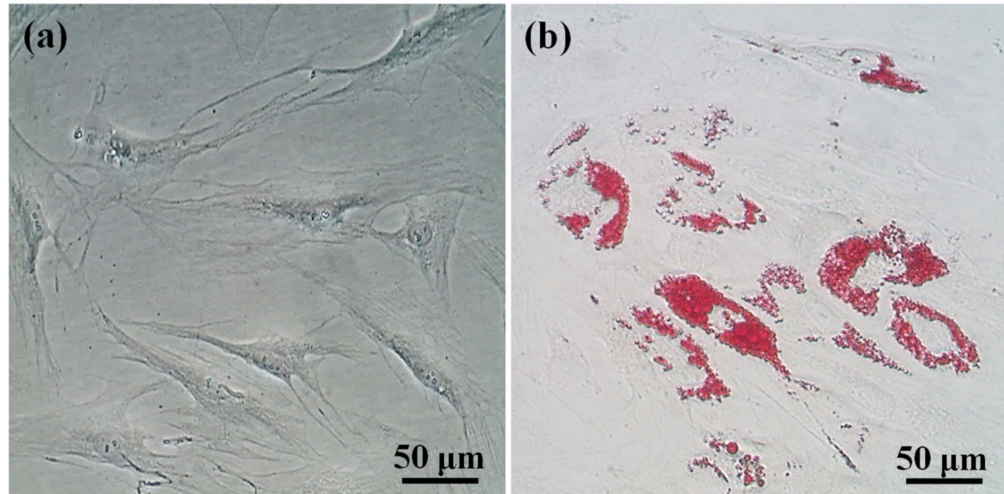

Figure 3. Optical micrographs of the human hair follicle-derived mesenchymal stem cells (HFMSCs) cultured with (a) normal medium and (b) adipogenic medium for 12 days (Oil Red O staining).
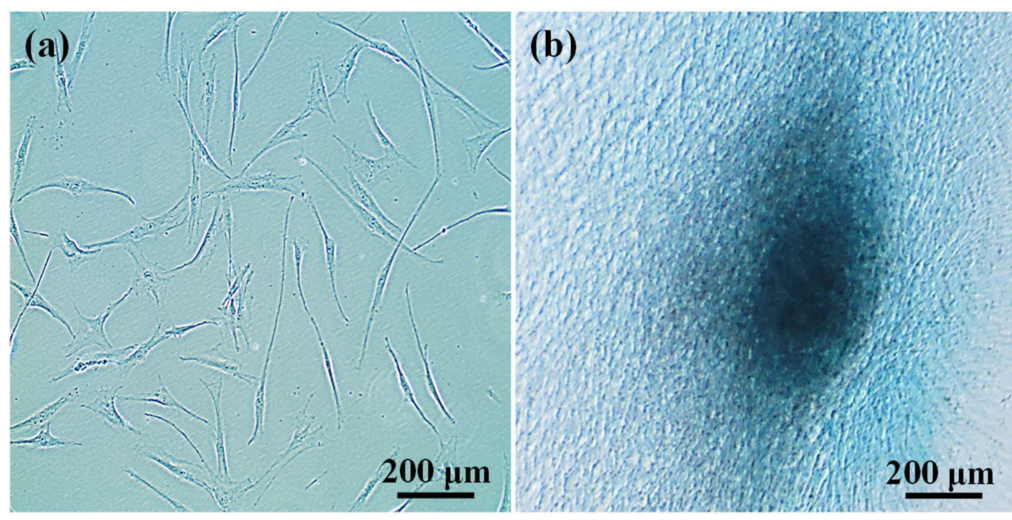

Figure 4. Optical micrographs of the HFMSCs cultured with (a) normal medium and (b) chondrogenic medium for 28 days (Alcian Blue staining). 


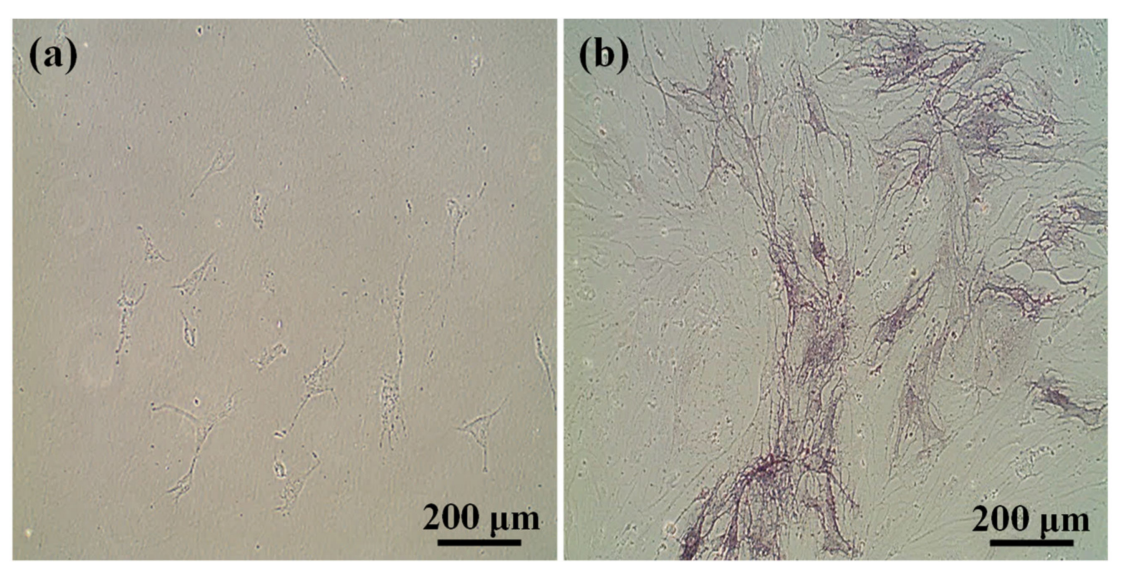

Figure 5. Optical micrographs of the HFMSCs cultured with (a) normal medium and (b) osteogenic medium for 28 days (Alkaline Phosphatase staining).

\subsection{Potential of 3BE Hydrogel to Enhance Cell-to-Cell Interaction of Swiss 3T3 and HFMSCs}

To further evaluate the cell behaviors within the 3D cell culture model, the Swiss 3T3 and HFMSCs were cultured in the investigated 3BE hydrogels with different concentrations for various durations. The cell growth as well as the cell attachment were examined using bright-field images following seeding. Figure 6 displays that Swiss 3T3 and HFMSCs formed aggregate or spheroid structures at day 1 and day 4, however, the Swiss 3T3 were observed to gradually disperse into a single cell at day 7 without spreading inside the dishes (Figure 6a). As for HFMSCs, different results were found at day 7 , the cells lumps were gradually spread out and attached to Petri dishes as shown in Figure 6b. These findings indicated that the derivatives of the 3BE hydrogel could improve the cell-to-cell interaction and promote the cells to aggregate into 3D spheres. For the cell viability observation, the Live/Dead staining was conducted on Swiss 3T3 and HFMSCs. The effect of the 3BE hydrogel concentrations on the cell viability of Swiss 3T3 and HFMSCs was observed under the fluoresce microscope. Figure 7 shows the mortality of Swiss 3T3 and HFMSCs were elevated with the increasing concentration of the 3BE derivatives. Although Swiss 3T3 and HFMSCs could form a 3D mass at day 4 as depicted in Figure 7a, it was apparent that Swiss $3 \mathrm{~T} 3$ had obvious death in the same concentration range with HFMSCs (Figure 7b). Figure 8 illustrates the survival rate of Swiss 3T3 and HFMSCs cultured in different concentrations of the 3BE hydrogel for 1 day, 4 days, and 7 days. It is clearly seen that the survival rate of Swiss 3T3 was the highest on the first day and was found to be measly on other days (Figure 8a). Moreover, although the survival rate of Swiss 3T3 was high at day 1, the cell viability rate was still lower than $70 \%$ in all groups. Conversely, in the HFMSCs group, the survival rate of these cells could be maintained over $70 \%$ until seven days of culture in each concentration of the 3BE hydrogel except in the 3BE-4 group (Figure $8 \mathrm{~b}$ ). Based on this result, the 3BE hydrogel played a crucial role in influencing the cell dividing rate because RGD in hydrogels can enhance cell adhesion and growth, and the synthetic hydrogel scaffold has the ability to mimic the dimensions of the ECM to support cell proliferation and migration. In this way, the 3BE hydrogel provides better cellular characteristics of an in vivo 3D environment for the HFMSCs. Accordingly, the experimental results reflected that the 3BE hydrogel is suitable to maintain the growth and proliferation of HFMSCs. 


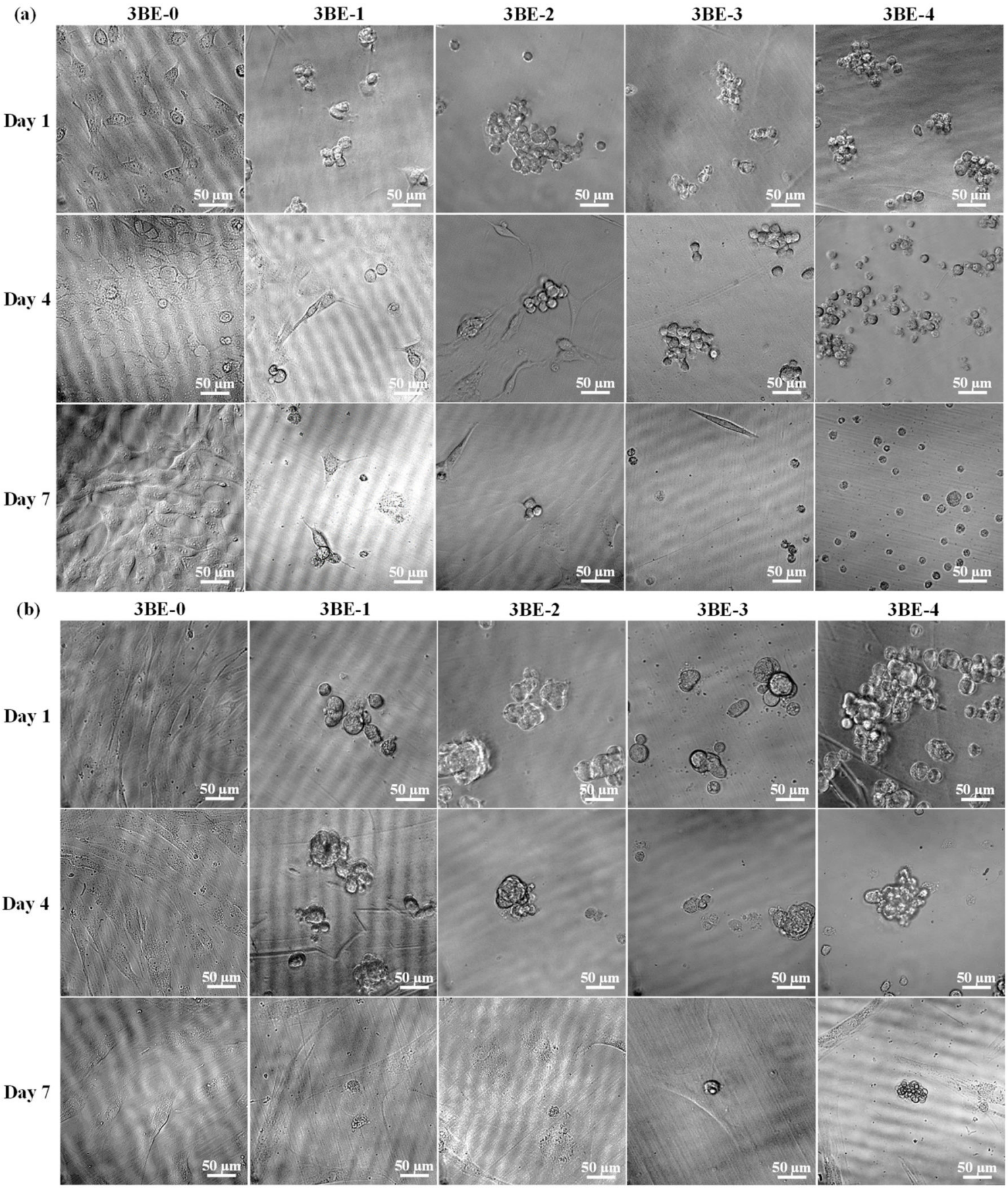

Figure 6. The morphology of the cells cultured in different concentrations of the 3BE hydrogel at day 1 , day 4, and day 7: (a) Swiss 3T3 and (b) HFMSCs. 


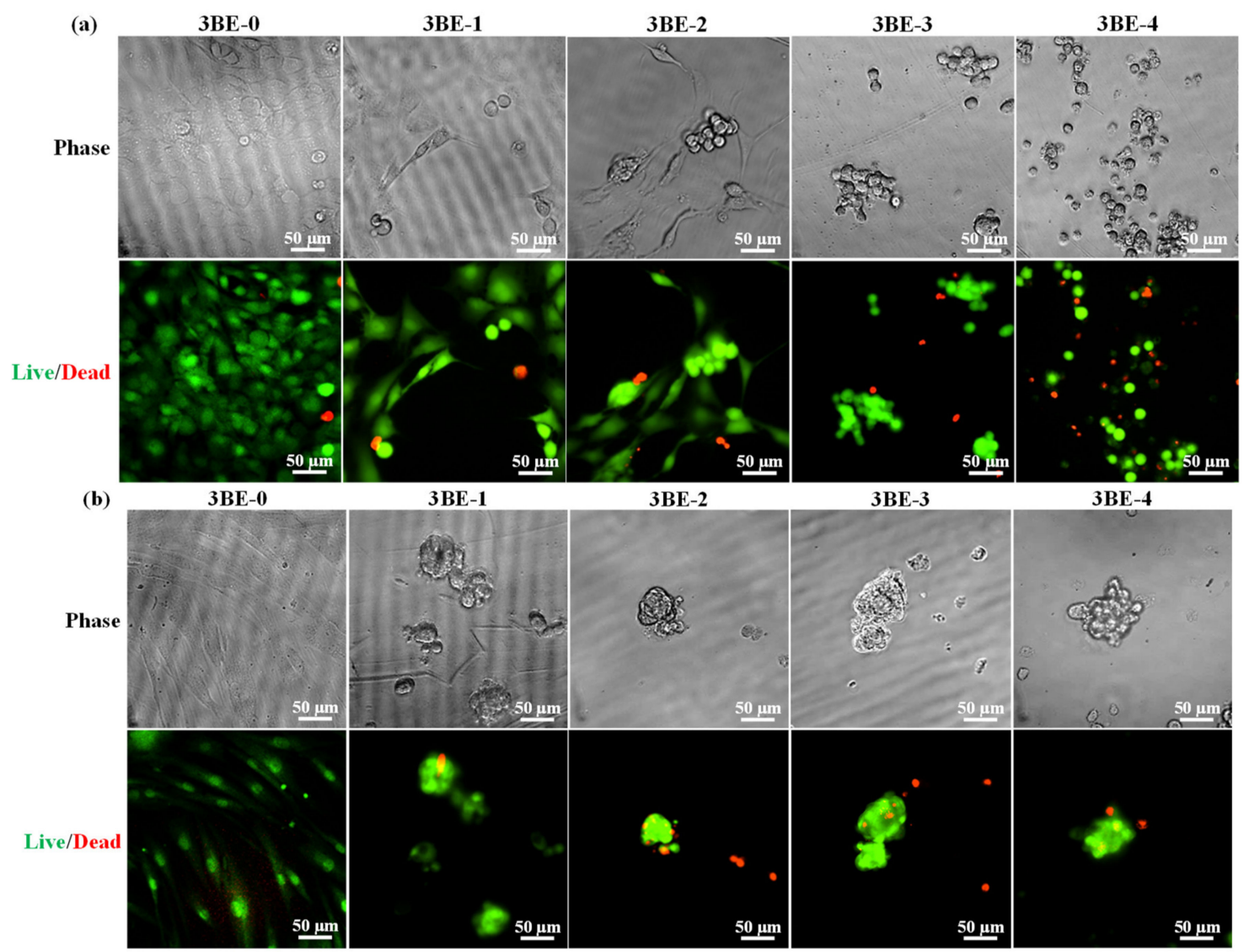

Figure 7. Live/Dead staining evaluation after culturing the cells in different concentrations of the 3BE hydrogel for 4 days: (a) Swiss 3 T3 and (b) HFMSCs.

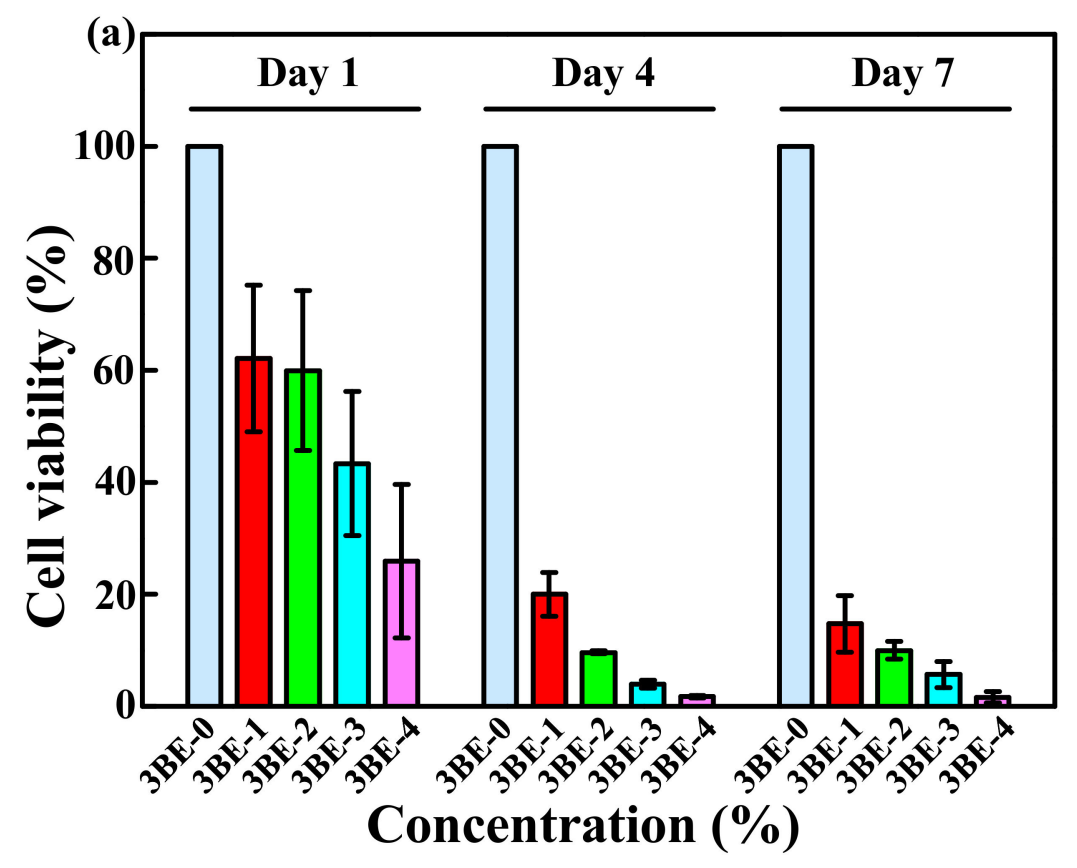

Figure 8. Cont. 


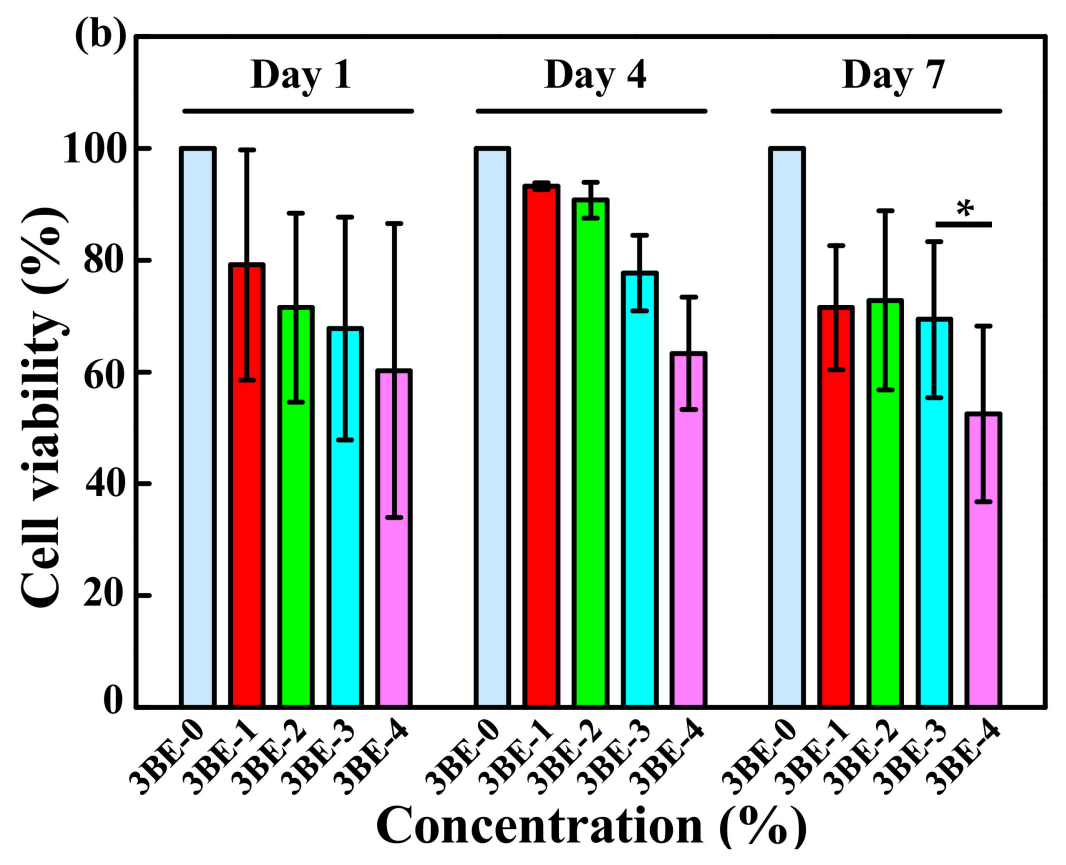

Figure 8. Effect of the 3BE hydrogel with different concentrations on the cell growth evaluated by using CCK assay on day 1 , day 4 , and day $7(n=3)$ : (a) Swiss 3T3 and (b) HFMSCs. $\left({ }^{*} p<0.05\right)$.

\section{Discussion}

In this study, we evaluated whether the extracted MSCs from human hair follicles have multiple differentiation potentials. Based on the previous studies, the main criteria of cells to be defined as multipotent is their ability to differentiate into various lineages such as chondrogenic, osteogenic, and adipogenic [21,22]. Therefore, we tested the differentiation capacity of HFMSCs in three different lineages. It was found that HFMSC changed its morphology inside the adipogenic, chondrogenic, and osteogenic differentiation mediums, projecting its multi-differentiation potential, while the differentiation morphology of HFMSCs exhibited a morphological similarity to MSCs [23]. During adipogenic differentiation, it is considered that as long as adipocytes are mature, the oil droplet will be formed in culture MSC $[19,20]$. In our study, the mature adipocytes were observed inside the adipogenic medium before day 12 indicated by the droplet formations. Moreover, we also evaluated the ability of HFMSC to differentiate into chondrocyte and osteocyte. Previous studies found that after chondrogenic differentiation, MSCs will gradually condense into a compact structure and can be stained using immunofluorescence [20,21]. Additionally, mature chondrocytes can also be detected with a glycosaminoglycan marker by Alcian Blue staining [21]. In line with this study, we found HFMSC showed a positive result for Alcian Blue staining. The chondrogenic medium can induce the aggregation of HFMSCs then gradually condense into compact structures. We also discovered that the osteogenic transformation of HFMSCs can be triggered through the osteogenic differentiation medium. Therefore, our results indicated that the isolated HFMSCs have the ability to differentiate into adipocytes, chondrocytes, and osteocytes.

It is generally believed that the cell adherence in vitro can be facilitated using various combinations of biomaterials $[12,24,25]$. One approach to this requirement is the establishment of hydrogels via molecular self-assembly of peptides and their derivatives [26,27]. It has been verified that hydrogels comprise an intrinsic hydrate architecture that imitates the mechanical properties of soft tissue and ECM $[28,29]$. Nevertheless, some limitations of the hydrogels such as leak of protein adsorption made this material sometimes poorly promote a direct adherence of the cells [30,31]. The present study indicated that the derivatives of hydrogel peptide could promote the cells to aggregate into 3D spheres. In addition, we found that the modification of GRGD with F127 could urge the cells to assemble and form a spheroid structure. Similarly, a previous study that used the mixture of F127 with 
RGD to culture the adipose-derived stem cells (ASCs) confirmed a higher cell adhesion of ASCs [14]. Supporting this finding, another study found that immobilization of RGD peptide onto macroporous scaffolds enable chondrogenesis of human MSCs by promoting cell adherence [17]. Although, the 3BE hydrogel could promote the cells to aggregate into 3D spheroids. Some of the spheroids exhibited a slightly irregular shape at this stage (Figure 6). The formation of this feature can be attributed to the influence of nutrient and oxygen gradients along with diffusion kinetics [32]. These are also factors to be considered and overcome when culturing cells in 3D, especially as the uniform size of the cellular aggregate grows using the 3BE hydrogel in the future.

Furthermore, it was found that the utilization of Pluronic F127 as a 3D cell culture substrate is suitable to maintain the growth of HFMSCs. The addition of membrane-stabilizing agents in Pluronic F127 results in maintenance of cell viability over time [13]. Furthermore, a study in which dental pulp-derived stem cells incorporated with some growth factors and polymer-peptide proved that this combination can assist cell proliferation, differentiation, and angiogenesis [33]. Underlining this result, a former study also confirmed the existence of cell adhesive RGD in hydrogels to promote cell adhesion and proliferation [27]. Cell adhesive RGD peptides are well known to enhance protein adsorption when applied in cell culture models [34]. After seven days of culturing, only the survival rate of HFMSCs at 3BE-4 was lower than $70 \%$ in all groups, which revealed that HFMSCs were probably suitable for growth in a concentration lower than $0.5 \%$. Accordingly, a mechanism of stem cells cultured in the 3BE hydrogel can be deduced as shown in Figure 9. The modified GRGD peptide can induce stem cells self-assembly. First, the individual cells were assembled to form the small cell clusters. Subsequently, the adjacent cell clusters aggregated to form a spheroid shape. These findings correlated with a previous study that found that MSCs grown on the RGD-containing nonporous PEGDA hydrogels were able to maintain a high number of cells [28]. Another study also confirmed that immobilized cy-RGD within the HA-g-Pluronic hydrogel was likely to stimulate cell proliferation and ECM production of bovine chondrocytes in vitro [30]. As stated above, the study uncovered that the GRGD modified Pluronic F-127 copolymer can enhance cellular adhesion of HFMSCs, representing the great potential of the 3BE hydrogel as a scaffold for 3D cell culture applications. Finally, more experiments should be performed to provide scientific information concerning the differentiation capability in the presence of 3BE hydrogel.

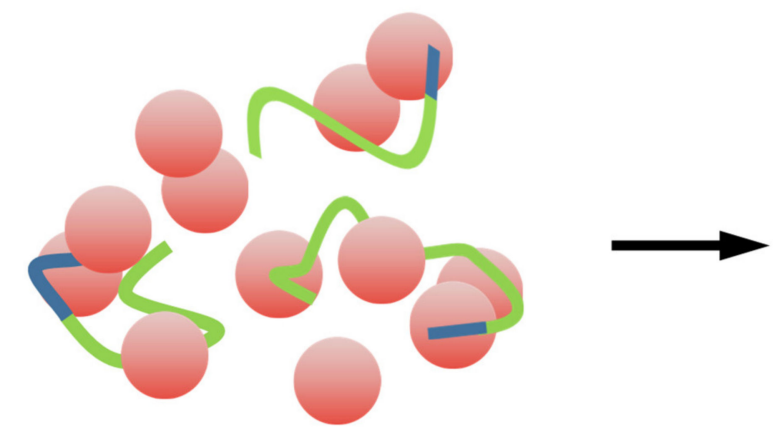

Stem cells cultured in the $3 B E$ hydrogel

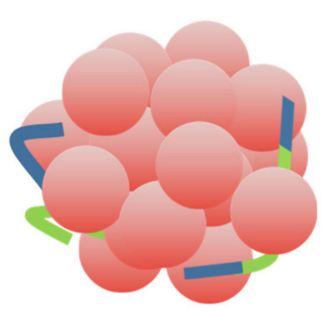

Spheroid formation

\section{Stem cells}

3BE hydrogel

Figure 9. A schematic diagram of the mechanism of stem cells cultured in the 3BE hydrogel.

\section{Conclusions}

The present study demonstrated the high potential of GRGD combined with Pluronic F-127 copolymer hydrogel to culture different cell lines three-dimensionally. The survival rate of HFMSCs could be greatly maintained indicating this material is ideal to facilitate the growth and proliferation of the MSCs. In addition, the spheroid structures of cells formed in the 3BE hydrogel may forecast the 
potential use of this material as a highly promising substrate to promote the differentiation of HFMSCs. The possibility to apply the 3D spheroid culture method to enhance cell differentiation would open up new perspectives in tissue engineering fields.

Author Contributions: Investigation, Y.-C.C. and H.-T.H.; data curation, C.-H.T. and B.-H.H.; methodology, W.-C.L.; conceptualization, M.-S.H.; supervision, T.S.; validation, F.-Y.F.; writing-original draft, Y.-C.C.; writing-review and editing, K.-L.O. All authors have read and agreed to the published version of the manuscript.

Funding: The authors would like to thank the Small and Medium Enterprise Administration, Ministry of Economic Affairs, Taiwan for financially supporting this research under contract No. 1Z1070291.

Acknowledgments: The authors would like to thank Woan-Ruoh Lee for her helpful advice and technical support in this paper.

Conflicts of Interest: The authors declare no conflict of interest in this work.

\section{References}

1. Hashemi, M.; Kalalinia, F. Application of encapsulation technology in stem cell therapy. Life Sci. 2015, 143, 139-146. [CrossRef] [PubMed]

2. Hutmacher, D.W. Scaffold design and fabrication technologies for engineering tissues-State of the art and future perspectives. J. Biomater. Sci. Polym. Ed. 2001, 12, 107-124. [CrossRef] [PubMed]

3. Tsou, Y.-H.; Khoneisser, J.; Huang, P.-C.; Xueqing, Z. Hydrogel as a bioactive material to regulate stem cell fate. Bioact. Mater. 2016, 1, 39-55. [CrossRef] [PubMed]

4. Moschella, J.; Kreiner, D.; Pena, J.; Zapantis, G.; Bolkas, M. Cumulus cell co-culture in the treatment of IVF patients with poor prognosis due to advanced maternal age or two or more failed previous cycles. Fertil. Steril. 2007, 88, S323. [CrossRef]

5. Torras, N.; García-Díaz, M.; Fernández-Majada, V.; Martínez, E. Mimicking Epithelial Tissues in ThreeDimensional Cell Culture Models. Front. Bioeng. Biotechnol. 2018, 6. [CrossRef]

6. Duval, K.; Grover, H.; Han, L.-H.; Mou, Y.; Pegoraro, A.F.; Fredberg, J.; Chen, Z. Modeling Physiological Events in 2D vs. 3D Cell Culture. Physiology 2017, 32, 266-277. [CrossRef]

7. Luzhansky, I.D.; Schwartz, A.D.; Cohen, J.D.; MacMunn, J.P.; Barney, L.E.; Jansen, L.E.; Peyton, S.R. Anomalously diffusing and persistently migrating cells in 2D and 3D culture environments. APL Bioeng. 2018, 2, 026112. [CrossRef]

8. Ravi, M.; Paramesh, V.; Kaviya, S.; Anuradha, E.; Solomon, F.P. 3D Cell Culture Systems: Advantages and Applications. J. Cell. Physiol. 2015, 230, 16-26. [CrossRef]

9. Chaudhuri, O. Viscoelastic hydrogels for 3D cell culture. Biomater. Sci. 2017, 5, 1480-1490. [CrossRef]

10. McKee, C.; Chaudhry, G.R. Advances and challenges in stem cell culture. Colloids Surfaces B Biointerface. 2017, 159, 62-77. [CrossRef]

11. Huang, X.; Zhang, X.-Y.; Wang, X.; Wang, C.; Tang, B. Microenvironment of alginate-based microcapsules for cell culture and tissue engineering. J. Biosci. Bioeng. 2012, 114, 1-8. [CrossRef] [PubMed]

12. Turnbull, G.; Clarke, J.; Picard, F.; Riches, P.; Jia, L.; Han, F.; Li, B.; Shu, W. 3D bioactive composite scaffolds for bone tissue engineering. Bioact. Mater. 2018, 3, 278-314. [CrossRef] [PubMed]

13. Khattak, S.F.; Bhatia, S.R.; Roberts, S.C. Pluronic F127 as a Cell Encapsulation Material: Utilization of Membrane-Stabilizing Agents. Tissue Eng. 2005, 11, 974-983. [CrossRef] [PubMed]

14. Kim, M.R.; Park, T.G. Temperature-responsive and degradable hyaluronic acid/Pluronic composite hydrogels for controlled release of human growth hormone. J. Control. Release 2002, 80, 69-77. [CrossRef]

15. Chen, W.-J.; Huang, J.-W.; Niu, C.-C.; Chen, L.-H.; Yuan, L.-J.; Lai, P.-L.; Yang, C.-Y.; Lin, S.-S. Use of fluorescence labeled mesenchymal stem cells in pluronic $\mathrm{F} 127$ and porous hydroxyapatite as a bone substitute for posterolateral spinal fusion. J. Orthop. Res. 2009, 27, 1631-1636. [CrossRef] [PubMed]

16. Diniz, I.M.A.; Chen, C.; Xu, X.; Ansari, S.; Zadeh, H.H.; Marques, M.M.; Shi, S.; Moshaverinia, A. Pluronic F-127 hydrogel as a promising scaffold for encapsulation of dental-derived mesenchymal stem cells. J. Mater. Sci. Mater. Med. 2015, 26, 1-10. [CrossRef]

17. Re'em, T.; Tsur-Gang, O.; Cohen, S. The effect of immobilized RGD peptide in macroporous alginate scaffolds on TGF beta 1-induced chondrogenesis of human mesenchymal stem cells. Biomaterials 2010, 31, 6746-6755. [CrossRef] 
18. LeCarpentier, Y.; Kindler, V.; Bochaton-Piallat, M.-L.; Sakic, A.; Claes, V.; Hébert, J.-L.; Vallée, A.; Schussler, O. Tripeptide Arg-Gly-Asp (RGD) modifies the molecular mechanical properties of the non-muscle myosin IIA in human bone marrow-derived myofibroblasts seeded in a collagen scaffold. PLOS ONE 2019, 14, e0222683. [CrossRef]

19. Bajpai, V.K.; Mistriotis, P.; Andreadis, S.T. Clonal multipotency and effect of long-term in vitro expansion on differentiation potential of human hair follicle derived mesenchymal stem cells. Stem Cell Res. 2012, 8, 74-84. [CrossRef]

20. Hoogduijn, M.J.; Gorjup, E.; Genever, P.G. Comparative Characterization of Hair Follicle Dermal Stem Cells and Bone Marrow Mesenchymal Stem Cells. Stem Cells Dev. 2006, 15, 49-60. [CrossRef]

21. Zhang, X.; Wang, Y.; Gao, Y.; Liu, X.; Bai, T.; Li, M.; Li, L.; Chi, G.; Xu, H.; Liu, F.; et al. Maintenance of high proliferation and multipotent potential of human hair follicle-derived mesenchymal stem cells by growth factors. Int. J. Mol. Med. 2013, 31, 913-921. [CrossRef] [PubMed]

22. Liu, J.Y.; Peng, H.F.; Gopinath, S.; Tian, J.; Andreadis, S.T. Derivation of Functional Smooth Muscle Cells from Multipotent Human Hair Follicle Mesenchymal Stem Cells. Tissue Eng. Part. A 2010, 16, 2553-2564. [CrossRef] [PubMed]

23. Danti, S.; D’Acunto, M.; Trombi, L.; Berrettini, S.; Pietrabissa, A. A Micro/Nanoscale Surface Mechanical Study on Morpho-Functional Changes in Multilineage-Differentiated Human Mesenchymal Stem Cells. Macromol. Biosci. 2007, 7, 589-598. [CrossRef] [PubMed]

24. Dumbleton, J.; Agarwal, P.; Huang, H.; Hogrebe, N.J.; Han, R.; Gooch, K.J.; He, X. The effect of RGD peptide on 2D and miniaturized 3D culture of HEPM cells, MSCs, and ADSCs with alginate hydrogel. Cell. Mol. Bioeng. 2016, 9, 277-288. [CrossRef]

25. Richards, D.; Jia, J.; Yost, M.; Markwald, R.; Mei, Y. 3D Bioprinting for Vascularized Tissue Fabrication. Ann. Biomed. Eng. 2017, 45, 132-147. [CrossRef]

26. Wang, Y.; Liu, J.; Tan, X.; Li, G.; Gao, Y.; Liu, X.; Zhang, L.; Li, Y. Induced Pluripotent Stem Cells from Human Hair Follicle Mesenchymal Stem Cells. Stem Cell Rev. Rep. 2013, 9, 451-460. [CrossRef]

27. Yue, K.; Santiago, G.T.-D.; Alvarez, M.M.; Tamayol, A.; Annabi, N.; Khademhosseini, A. Synthesis, properties, and biomedical applications of gelatin methacryloyl (GelMA) hydrogels. Biomaterials 2015, 73, 254-271. [CrossRef]

28. Keskar, V.; Marion, N.W.; Mao, J.J.; Gemeinhart, R.A. In Vitro Evaluation of Macroporous Hydrogels to Facilitate Stem Cell Infiltration, Growth, and Mineralization. Tissue Eng. Part A 2009, 15, 1695-1707. [CrossRef]

29. Lippens, E.; Swennen, I.; Girones, J.; Declercq, H.; Vertenten, G.; Vlaminck, L.; Gasthuys, F.; Schacht, E.; Cornelissen, R. Cell survival and proliferation after encapsulation in a chemically modified pluronic(r) f127 hydrogel. J. Biomater. Appl. 2013, 27, 828-839. [CrossRef]

30. Lee, H.; Park, T.G. Photo-crosslinkable, biomimetic, and thermo-sensitive pluronic grafted hyaluronic acid copolymers for injectable delivery of chondrocytes. J. Biomed. Mater. Res. Part. A 2009, 88, 797-806. [CrossRef]

31. Lin, J.-Y.; Lin, W.-J.; Hong, W.-H.; Hung, W.-C.; Nowotarski, S.H.; Gouveia, S.M.; Cristo, I.; Lin, K.-H. Morphology and organization of tissue cells in 3D microenvironment of monodisperse foam scaffolds. Soft Matter 2011, 7, 10010-10016. [CrossRef]

32. Cui, X.; Hartanto, Y.; Zhang, H. Advances in multicellular spheroids formation. J. R. Soc. Interface 2017, 14. [CrossRef] [PubMed]

33. Galler, K.M.; Hartgerink, J.D.; Cavender, A.C.; Schmalz, G.; D'Souza, R.N. A Customized Self-Assembling Peptide Hydrogel for Dental Pulp Tissue Engineering. Tissue Eng. Part. A 2012, 18, 176-184. [CrossRef] [PubMed]

34. Hersel, U.; Dahmen, C.; Kessler, H. RGD modified polymers: Biomaterials for stimulated cell adhesion and beyond. Biomaterials 2003, 24, 4385-4415. [CrossRef]

Publisher's Note: MDPI stays neutral with regard to jurisdictional claims in published maps and institutional affiliations. 